\title{
Innovation in education: problems and ways of their solution
}

\author{
Uliana Milhaleva ${ }^{1, *}$ \\ ${ }^{1}$ Don State Technical University, Gagarin sq., 1, Rostov-on-Don, 344003, Russia
}

\begin{abstract}
This article analyzes the problems of modern education, and on the basis of this analysis, a search for a new approach to the formation of not only necessary knowledge, but also skills in the learning process is conducted. It will be about contextual, crosscontextual and existential skills, their improvement and transformation. Such skills should be developed in modern educational centers, which, in turn, should become the starting point of an individual educational route. It is the individual approach and new technologies that will help to form a personality adapted to professional activities in a rapidly changing world. The article also classifies the factors affecting the modern education system, they are divided into three main groups: social, technological and geopolitical. This classification, in turn, is used to study the strategies of innovative development of the educational system in Russia.
\end{abstract}

\section{Introduction}

Modern researchers, specialists and managers in the system of educational relations do not doubt that the education system must change. This is due to the ongoing global changes that are increasing the gap between the learning outcomes of modern graduates and the requirements for the set of competencies of current and future employees. In the course of the innovative development of education, such problems remain relevant: a high degree of anxiety among schoolchildren accompanying the choice of a "professional life path", one profession "for life" under the pressure of conservative teachers and parents (who grew up in an outdated paradigm); dissatisfaction of graduates with the choice of profession, neurotic states, negative emotions associated with the opportunity to make the wrong choice.

\section{Main part}

${ }^{*}$ Corresponding author: uralochkka@mail.ru 
The existing forms of career guidance designed to help students in professional selfdetermination create a certain paradox: the higher the awareness, the higher the anxiety in the rapidly developing world. Thus, the main achievement of secondary school, according to the author, is the willingness and desire to receive continuous education with cognitive interest as a steady need to develop and expand one's knowledge.

Based on years of research, European scientists describe the future world with the abbreviation VUCA, which means: variability, uncertainty, complexity, ambiguity.

According to WorldSkills Russia and Global Educational Futures development groups, which are engaged in predicting the image of future professions and selecting appropriate competencies, changes in educational systems will occur under the influence of global innovations.

1. Technological trends:

digitalization (Internet of Things, Big Data, Artificial Intelligence);

automation and robotization (cyber-physical systems, automation of cognitive and physical labor);

2. Social trends:

demographic changesя (an increase in life expectancy and age of the active working-age population, a decrease in the number of young people of working age; changing roles of women and childhood patterns);

networking community (networking, meaningful consumption, gamification);

3. Techno-social trends:

globalization (economy, knowledge, technology);

greening (education for sustainable development).

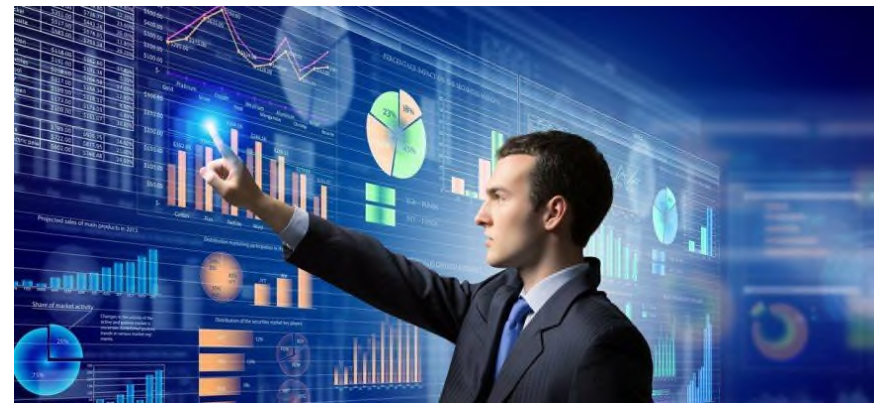

Fig. 1. Innovative technologies

All positions are influenced by one megatrend - an exponential acceleration of the rate of change.

In this context, groups of skills critical to future success emerge. Partnership for $21 \mathrm{st}$ Century Skills, Curriculum Redesign Center, Skolkovo Scholars and others have attempted to identify a list of core 21st Century skills: concentration and control of attention; emotional intellect; digital literacy; creativity; ecological thinking; cross-culture; selfeducation.

According to these researchers, there is an objective need to find a new approach to building a skills model. Instead of hard skills and soft skills, it is suggested to consider contextual (specialized), cross-contextual and existential skills. Contextual skills are required to perform job functions in specific professional areas and exist with those functions and operations. With a change in technology, or in the case of replacing human labor with machine labor, highly specialized skills are gradually disappearing. Crosscontext skills have a longer life cycle and can be used in a variety of fields. This is the foundation of effective human activity. As existential skills are used by a person throughout 
life in various contexts, they are improved and transformed. For example, willpower, goalsetting, reflection. Their relevance increases with age.

Fundamentally new result cannot be obtained on the basis of the traditional approach. Thus, the problem arises of revising the approaches, forms and methods of teaching and the organization of the educational process. However, today the values of the last century prevail in educational systems: one education for life, a long stay as an employee of one organization, unification, monotony of operations, linearity in training and work. The challenges of the 21 st century require a radical change in the educational paradigm towards the development of creativity, planning of activities, the implementation of multidirectional projects, and management of human, information and material resources.

Skills obsolescence is faster than education. The educational paradigm must address the personality of the student even more than has been postulated since the beginning of the era of the development of humanism, in order to reveal the unique potential of each person. This is hindered by the implementation of standard tasks, the prohibition or restriction of initiatives, the strong separation of various educational institutions, which does not contribute to the understanding of education as a single ecosystem.

But there is some progress in this direction. Educational organizations are gradually becoming a place open to different age groups and people with special needs, comfortable for families. There is a tendency to move schools and universities into the status of basic platforms or "points of application" that serve as the starting point of an individualized educational route. Some of the educational content is posted on electronic educational platforms, freeing up time for practice. The most important change is the change in the role of teachers and an understanding of the multiplicity of sources of knowledge, awareness of the need for lifelong education.

Let's look at data from the Institute for the Future, a nonprofit independent research group for the University of Phoenix Research Institute and the Apollo Research Institute in California. The developers identify 6 key innovations that will determine the further development of the education system:

Table 1. Key innovations

\begin{tabular}{|c|c|c|}
\hline № & Key innovations & Development of the education system \\
\hline 1. & Extraordinary longevity & $\begin{array}{c}\text { The number of the working-age population } \\
\text { over } 60 \text { is increasing. Career and education } \\
\text { approaches must also change. }\end{array}$ \\
\hline 2. & $\begin{array}{c}\text { Development of smart machines } \\
\text { and systems. }\end{array}$ & $\begin{array}{c}\text { What can only humans do? Where is the } \\
\text { place of man in the world of machines? }\end{array}$ \\
\hline 3. & Computing world & $\begin{array}{c}\text { Big Data and processing methods create the } \\
\text { basis for the formation of special thinking- } \\
\text { thinking based on data analysis when making } \\
\text { decisions (data-based decisions); using Big Data } \\
\text { to predict scientific development (design } \\
\text { outcomes) }\end{array}$ \\
\hline 4. & New media ecology & $\begin{array}{c}\text { Text media are being transformed by the } \\
\text { ever-increasing influence of infographics and } \\
\text { other visual communication tools. }\end{array}$ \\
\hline 5. & Superstructure organizations & $\begin{array}{c}\text { Organizations are restructuring in } \\
\text { accordance with the laws of game design, } \\
\text { neurobiology and psychology of happiness, } \\
\text { forming a new management model. }\end{array}$ \\
\hline 6. & Globally connected world & Open space creates new ethic of interaction. \\
\hline
\end{tabular}

It can be noted that the key driving forces of development put the principle of lifelong education as an objective imperative. In accordance with the above areas, researchers 
deduce 10 key competencies that ensure the success of a person's self-realization in various fields of activity:

1. Making sense. Innovative, creative thinking, unique ideas, "new meanings" will be in demand.

2. Computational thinking will be needed to interpret big data and create abstract models in the imagination.

3. Social intelligence, as the ability to effectively interact and build communication with other people based on developed emotional intelligence.

4. The novelty and adaptability of thinking, as the ability to find creative solutions to nonstandard problems and respond to constant situational changes. Separate direction in the higher education system is developing in the Russian Federation. This is called the theory and practice of innovation management, pedagogical innovation.

5. New media literacy. When there is too much information, there is a need for critical thinking, analytical skills and creation of new content with a visual dominance.

6. Intercultural competence, as the ability not only to interact with representatives of other cultures, but also to understand the characteristics of different cultures and foster a tolerant attitude towards them. It is important to understand that intercultural literacy is necessary for not only travel or work abroad, but will also be necessary for almost everyone who will be part of large planetary superstructural organizations.

7. Transdisciplinarity. Solving modern practical problems requires competence in various subject areas.

8. Design thinking or creative thinking, the ability to transform reality in accordance with the desired result.

9. Virtual collaboration. Working in superstructural organizations will allow companies to bring together employees located in different countries and continents to solve similar problems.

10. Cognitive load management as the ability to cope with the information flow, differentiate tasks, plan activities and reduce cognitive load using specially developed techniques.

By systematizing the results of various studies, the author has attempted to classify key trends and future skills, as well as a number of other factors affecting the modern education system.

The education system in Russia is developing under the influence of the requirements of the Federal State Educational Standard (FSES), social demand from parents (legal representatives) and students themselves, who have expectations that differ from the typical expectations of previous generations. Large companies also have requirements for the competence of graduates.

Three groups of key tendencies or "drivers of change" can be distinguished among the factors influencing the modern education system:

1. Social trends. The age and sex composition of the working population is changing. The proportion of employees aged 65 and over is growing. Among young people, these data are mixed. Some of them, as a rule, start building their careers earlier, take an active part in government projects, develop as volunteers, and look for business connections. Others, in a situation of volatility and instability, do not seek to start working.

Mediaecology as a special science studies special types of communication (not only the interaction of subjects, but also the communicative component of objects and environments).

2. Technological trends. There is a process of widespread automation and robotization, which raises questions about the place of man in the world of machines and the "new" ethics of interaction with "artificial intelligence" systems. 
3. Geopolitical trends reflect modern desire to create open systems and raise a range of problems related to cross-culture, mobility, and work of global corporations.

All these processes are influenced by the general mega-trend acceleration. In an attempt to answer the question "What skills will help you become successful," the researchers propose a set of core competencies that, in their opinion, will solve problems of mobility, flexibility and adaptability.

The need to ensure the country's competitiveness in the international arena poses an obvious problem of the formation of human capital with all the above characteristics and competencies that would allow it to adapt to new requirements in the future.

The report presented at the 37th session of the UN General Conference on Sustainable Development "Medium-Term Strategy: 2014-2021" emphasizes the need for cooperation and synergies in joint research and overcoming isolation and fragmentation of programs ("Medium-Term Strategy: 2014- 2021").

An interesting position is the priority of personnel rotation, decentralization of specialists and focus on the needs of the regions. Mechanisms of personnel rotation and renewal of teams, the creation of network communities are being introduced in Russia. The motivation to innovate is an "effective contract of employment" that sets incentives and performance criteria.

An important step towards international cooperation in improving education systems and shaping the image of the future was the study by the international company The Boston Consulting Group (BCG), which also includes Russian analysts.

The company conducted extensive interviews with top management representatives of the world's largest companies, as well as with Russian employers. One of the directions of the study was to identify the expectations of employers in relation to future employees and their requirements in the context of the priority areas of company development. The starting point is a gradual focus on the "knowledge economy", where people with high cognitive abilities, developed abstract, design thinking, ability to act in conditions of constant change, both independently, and in working groups, can successfully act. At the same time, in Russia there is a low share of people employed in high-tech industries, which is due to the general lag of the education system from real practical problems.

Realizing the importance of high educational results for the country's prosperity, Russia begins to discuss a new long-term strategy for the development of education, defining its mission, key priorities and directions. For the first time, the development of the Strategy was entrusted not only to specialists of the Russian Academy of Sciences, but also to "practitioners", those people who daily solve pressing problems of education and upbringing - teachers and principals of schools, as well as parties directly interested in the level of training of future specialists - potential employers, large companies, businessmen.

Planning the Russian socio-economic development strategy for 2024-2035, the Higher School of Economics - National Research University and the Center for Strategic Research presented a report on 12 solutions for new education, realizing that the educational sector will become the basis of the future technology market ("12 solutions for new education").

According to the Global Human Capital Report 2017, Russia ranks very high 4th in the world in terms of human capital (measured mainly in terms of enrollment in various levels of formal education), but only 42nd in terms of actual use of skills and involvement in lifelong learning. At the same time, Russia ranks 89th in the world in terms of such an important indicator of economic growth as "availability of qualified specialists". The real impact of a formally high level of education on economic growth and its sustainability is very small. The reason is seen in the constant lack of funding, so the system can exist, but not develop.

In his Address dated March 1, 2018, the President of the Russian Federation announced the need to increase funding for the education system. "All the proposed scenarios for 
financing the development of the education system imply the digital transformation of education and the widespread use of public-private partnerships (hereinafter - PPP). There are practically no alternatives to these tools: results similar to digital education can be obtained on a traditional basis only by doubling the educational budget to $7 \%$ of GDP. In turn, PPP will allow "shifting" part of the budgetary expenditures for the period 2024-2030 and getting a modern school infrastructure in 2020-2022.

In Russia, there is also such a problem as the lack of a system for identifying and supporting talent in the field of high technology, design and natural sciences from the extracurricular program. Fewer than $40 \%$ of high school graduates, $20 \%$ of college graduates and $50 \%$ of university graduates have had experience in project work and social practice.

Researchers have proposed 12 projects to help solve these problems.

1. Support for early development through foster care for children 0-3 years old (disabled up to 6 years old). The work of specialists based on early identification and correction of developmental risks will reduce the percentage of children with a low degree of readiness to go to school.

2. "School of the digital age" includes new digital educational and methodological complexes that provide individualization, objectification of the assessment of achievements and a decrease in non-teaching load; introduction of educational games and simulators.

3. Modern material and educational infrastructure is the implementation of an ecological approach in education. School becomes an educational, cultural and sports center for children and adults.

4. Equal educational opportunities and success for everyone: preparation for school programs for preschool children; targeted assistance to low-income families; reducing inequality in educational opportunities.

5. New technological education in the system of school and secondary vocational education: modernization of the content of educational programs; creation of workshops, network forms of education, creation of youth centers for innovative and technical creativity and their integration, new forms of assessment.

6. Development and support of talents: specialized high-tech camps and schools; grant and scholarship support.

7. Launching the system of continuing education.

8. Universities as centers of innovation in regions: decentralization of specialists, financing of regions, support for innovative development.

9. Fundamental research at the Graduate School, global universities, the Russian Academy of Sciences: bringing universities to the international arena and implementing international projects, supporting graduate students.

10. Enhancing global competitiveness through the export of professional education: development of international exchange programs for undergraduates and postgraduates; creation of open educational platforms; formation of a modern educational environment.

11. Modern content of school education: updating the content of educational programs and methods.

12. Personnel for education development: updating the principles of human resource development.

These projects are undoubtedly within the competence of the Government of the Russian Federation. However, teachers can be challenged to find practical mechanisms and conditions for project implementation.

At present, a broad public discussion of the development strategy of Moscow education for the period up to 2025 has begun in Moscow, which is called "Strategy 2025". As a result of a series of strategic sessions in Moscow schools, four main directions of 
development were formulated and proposed to general public, which can become the basis for a strategy for the innovative development of education in Russia:

1. The system of personalized educational trajectories in open groups. This is an opportunity to draw up flexible curricula based on the needs and interests of each student, as well as provide an opportunity to engage in subject learning at various sites in the city (schools, resource centers, universities, colleges, youth creativity centers, etc.).

2. Distributed assessment in the talent system - assessment of students' achievements in various fields, followed by credit as an incentive for continuous multifaceted development. These can be subject and metasubject Olympiads and competitions, achievements in the field of sports, culture and art. All so-called "digital footprints" will become components of a single open portfolio. This system removes the school's monopoly on the assessment of graduates.

3. The city is like a school. Moscow is a space of unlimited opportunities for the development of talents, and a teacher-navigator in it. It is important to note that the programs offered by the city, implemented in organizations of different levels and directions, can and should be integrated into a class-oriented system. The school becomes the base organization for attaching students on a territorial basis and keeping their personal documents.

4. "City school" is the principle of the existence of a single map of the microdistrict resources, which allows you to receive quality education in all areas without the need for long daily trips.

These central ideas are supplemented, transformed and developed by the teaching staff. These are the main proposals made during the discussions and recorded in articles and reporting documents.

Future of education is seen in large-scale cooperation of various organizations to create an open educational environment, expand students' ideas about various professional environments, life and work in modern society. Network partnership, as a form of such interaction between organizations, creates conditions for joint activities, joint project management, development of human, innovative, technical, material potential.

Together with industrial organizations, business structures, educational institutions, it is possible to build a system of promising proposals based on the target model of future competencies, to include employers in the early vocational training system. An interesting practice is the conclusion of deferred employment contracts with a delayed start date. Employers invite students to solve cases. Technoparks and universities provide technical support in the implementation of design solutions. The best intellectual solutions are rewarded, and children with special talent are invited to the enterprise. Under the terms of this Agreement, child undertakes to enter university in the chosen specialty, and the company guarantees him the organization of practice and subsequent employment, but with a number of conditions for high-quality acquisition of knowledge and competencies.

For the system to work, it is necessary to introduce the following aspects: a unified open point-rating system for assessing educational and extracurricular results; offsetting the results of different organizations. All data must be entered into a virtual grade book, open to employers and universities.

The interests and opinions of all interested parties are constantly monitored. This is the Pedagogical Community, parents, students, employers.

At the same time, educational events are held, which include a specially organized lecture for the parent community, not only with comprehensive information about the changes taking place in the region in the context of education and subsequent employment, but also answers to all questions of interest. For students, meetings are organized with representatives of various professions (project "100 Questions for a Professional"); universities conduct interactive role-playing games and quests about professions. The 
teaching community also needs to constantly update its knowledge. Maximum clarity and openness is also achieved through information support, which is provided by timely notification of upcoming events, distribution of lecture materials, and publication of "feedback" after the events.

The result of regular work is competency maps and maps of partners' resource capabilities, which allow choosing the conditions for the development of any competencies. Let's consider the example of "classical" profiles: physical and mathematical, chemical and biological profiles.

Having analyzed the programs of initial vocational education and the first stage of higher vocational education, as well as based on the requirements of the Federal Standard, it is possible to draw up a detailed list of competencies that are formed in colleges and universities during the first year of study. The second source of material for competency maps is interviews with partners about the "portrait of a university entrant", as well as employing companies about changes and new types of activities.

The second aspect of analysis and second component of competency maps is the type of educational event, within the framework of which, to a greater or lesser extent, one or another competence can be formed. By comparing the capabilities of partners, as well as significant competencies for each profile, it is possible to build a trajectory of participation in educational events for them. Thus, digital competence, team time management and communication competence are most effectively formed in the process of "hackathons" and "designatons". Deepening of subject skills and knowledge is carried out with participation in the work of the university in the factory production. If we talk about the chemical and biological profile, then students who have chosen this profile to prepare for admission to a medical university can acquire the necessary skills and initial professional knowledge in the process of volunteering within the framework of the all-Russian movement "Volunteersdoctors", which works in city polyclinics. The map of resource capabilities of partners allows you to compile a detailed list of ways to obtain new knowledge, skills and abilities, as well as the formation of competencies in specific activities.

The level system of work organization and creation of environmental conditions for gaining practical experience in primary grades contribute to the implementation of the requirements of Federal standards.

Processes in city resource centers are adapted for similar events, actions, projects at school. One of these areas of work is the school volunteer center, which contains the same areas of work that are available to city volunteers who have personal volunteer books and take part in city projects. Work in the school volunteer center is available to students from the 4th grade (9-11 years old). Upon reaching the age of 14 , students receive city personal volunteer books.

Within the framework of the volunteer center, students get acquainted with the world of professions. Starting from the 8 th grade (in some projects, from the 7 th), students are involved in such new interaction formats as hackathon, design marathon, work in a production laboratory, etc. At the same time, potential employers are proposing real production challenges while watching the progress of finding a solution. The most successful ones can be invited by these companies for internships and other events, as well as receive a referral for targeted admission to a specialized university. In addition, participants gain new knowledge, practical experience, as well as an understanding of the specifics of activities in a particular professional field.

It is assumed that by the end of the 9th grade, graduates will have formed an idea of possible trajectories for building future educational and professional activities, one of the options for which is training in specialized classes. To meet the needs for career guidance, volunteering, primary professionalization, a system of relationships is organized through the implementation of special projects and programs. 
As a result, the following requirements of the standard are implemented:

1. Creation of special conditions. Network partners, within the framework of an agreement on scientific and methodological cooperation, offer to use their resource capabilities, both in terms of equipment, and in terms of laboratory and other specialized premises, which can significantly expand subject and metasubject skills, as well as form an idea of work and scientific activities.

2. Self-organization and planning. The implementation of their own projects, actions and programs, including voluntary ones, contributes to the development of self-organization skills, effective time management and planning of their activities and the activities of the project team.

3. Solving problems and setting goals in group and individual work, as well as the skills to apply the knowledge gained in practice.

4. Orientation in the scientific and professional world. A stay in specialized laboratories, resource centers and in production allows to get acquainted with real problems that professionals in various fields solve.

5. Primary professionalization. Existing state projects allow students to acquire primary professional knowledge and skills.

6. Scientific creativity. A large number of research competitions and projects for students allow them to contribute to their personal portfolio, receive a grant, attract attention of a potential employer and build a unique trajectory of professional development.

7. Social portrait of a graduate and a citizen.

Building these skill groups through networking is a guided process. We can highlight the following aspects:

1. Determination of the map of resource opportunities formed on the basis of the school resource capabilities, opportunities and proposed programs from partner organizations, maintenance of the district's infrastructure, urban educational projects and programs and their classification by areas (high technology, medicine and health care, biology and chemistry, psychology and pedagogy, patriotic education, etc.).

2. Determination of target groups: students with special needs, students of specialized and pre-profile classes; students with high aptitude and interest in certain types of learning activities.

3. Working out the process of working with each target group.

4. Collection of statistical data on the working results and the formation of interconnected databases.

Let's dwell on the key stages of working with target groups of students.

1. Professional testing and analysis of personality characteristics with the involvement of the school psychological service and partner organizations.

2. Formation of an individualized cloud of professions.

3. Discussion of an individual request and the search for optimal solutions that satisfy the development in the chosen direction.

4. Resource selection based on existing resource capacity maps.

5. Building a trajectory of movement for a certain period in accordance with the task.

6. Tutoring support and navigation in the urban environment.

7. Joint analysis of results and trajectory correction.

The substantive aspect of working with some categories of students:

assistance in choosing the direction of study in the 8th and 9th grades and assistance in changing the profile in the 10-11th grades;

selection of additional educational resources (including extracurricular);

select profile events;

mentoring, scientific leadership;

preparation and participation in educational activities; 
psychological support.

It is also important to work with grades of the $7-11^{\text {th }}$ grades and parents to become familiar with the following areas:

excursion work - universities, colleges, employers, professions, etc.; educational forum;

navigation through city events.

Key events tables in areas help you visually track which events have a decisive influence on the formation of various skills. Individual trajectories for groups or individual students are possible.

The tables allow to structure the "annual action plan" of various partner organizations, as well as city structures, and to rank these actions depending on the impact on the individual competencies formation.

\section{Conclusion}

Educational innovation has many challenges. This is due to the requirements of the participants in educational relations, the increasing demands of reality, including robotics, automation, the disappearance of old professions and the emergence of new professions and whole groups of specialties. There are issues not only of interpersonal interaction, but also of interaction with "smart machines and systems". Experiencing the influence of global trends, the education system must promptly make changes that would provide both the level of fundamental training and other new formations that give graduates the opportunity to find their place in the "new complex world." The space of a modern metropolis contains unlimited resources that can be used in the educational process under the guidance of a competent teacher.

Realizing the importance of human capital for the country's competitiveness, the Russian Federation has initiated a broad process of discussing an innovative strategy for the development of education, where the opinion of "practitioners" - teachers, school principals, employers, and business structures - plays the main role. On the basis of international research, it becomes possible to form maps of future skills, change the content of educational programs and curricula, and use new learning formats. The emphasis is on networking with partners, joint creation of programs. Education is becoming open and accessible.

\section{References}

1. «Medium-term strategy: 2014-2021». Doc. 37 C/4. UNESCO (2014) https://www.iaea.org/about/overview/medium-term-strategy (Last accessed 11.06.2020)

2. N. Bennett, G.J. Lemoine, What a difference a word makes: Understanding threats to performance in a VUCA world. Business Horizons 57(3), 311-317 (Netherlands: Elsevier, 2014)

3. J. Pellegrino, M. Hilton, Education for life and work: Developing transferable knowledge and skills in the 21st century. Washington 242 (DC: National Academies Press, 2012)

4. V. Stefanova Ratcheva, J. Riordan, M. Takahashi, Y. Thompson, J. Toscani, Y. Vijay, World Economic Forum. The Global Risks Report 2017 13rd ed. (2017) http://www.mmc.com/content/dam/mmc-web/Global-Risk- Center/Files/the-globalrisks-report-2018.pdf (Last accessed 11.06.2020) 
5. A. Raymond, E. Jacob, D. Jacob, J. Lyons, Peer Learning a Pedagogical Approach to Enhance Online Learning: A Qualitative Exploration. Nurse Education Today 44(C), 165-169 https://ro.ecu.edu.au/cgi/viewcontent.cgi?referer=https://www.google.ru/\&httpsredir=1 \&article $=3030 \&$ context $=$ ecuworkspost 2013 (Last accessed 11.06.2020)

6. B. McGaw, Developing 21st Century Competencies through Disciplines of Knowledge. Paper presented at an International Symposium on Education and 21st Century Competencies (Muscat, Sultanate of Oman, 22-24 September 2013) http://docs.acara.edu.au/resources/Developing_21st_century_competencies_Prof_Barr y_McGaw.pdf (Last accessed 11.06.2020)

7. Beyond Retrofitting: Innovation in Higher Education, ed. A.P. Kelly, 41 (F.M. Hess, Hudson Institute, June 2013)

8. S. Kolowich, The MOOC 'Revolution' May Not Be as Disruptive as Some Had Imagined The Chronicle of the Higher Education (2013) http://chronicle.com/article/MOOCs-May-Not-Be-SoDisruptive/140965/ (Last accessed 18.06.2020)

9. M. Anghela, Procedia - Social and Behavioral Sciences 142(14), 19-23 (2014) doi: 10.1016/j.sbspro.2014.07.580

10. S. Campbell, J.M. Twenge, W.K. Campbel, Fuzzy But Useful Constructs: Making Sense of the Differences Between Generations. Work, Aging and Retirement 3(2), 130-139 (2017) doi:10.1093/workar/wax001

11. A. Jameson, A. Karthia, C. McGuinness, F. MacSwinib, Procedia - Social and Behavioral Sciences 228, 515-522 (2016) doi:10.1016/j.sbspro.2016.07.079

12. J. Marcus, S. Ceylan, C. Ergin, Not So «Traditional» Anymore? Generational Shifts on Schwartz Values in Turkey. Journal of Cross-Cultural Psychology 48(1), 5874 (2016) https://doi.org/10.1177/0022022116673909

13. A. Corelli, Procedia - Social and Behavioral Sciences, Direct vs. Anonymous Feedback: Teacher Behavior in Higher Education, with Focus on Technology Advances 195, 52-61 (2015)

14. S. Schwartz, ed. V. Zeigler-Hill, T. Shackelford Encyclopedia of Personality and Individual Differences Springer, Cham (2019) https://doi.org/10.1007/978-3-31928099-8_2327-1

15. A.W. Lukaszewski, Extraversion, ed. V. Zeigler-Hill, T. Shackelford, Encyclopedia of Personality and Individual Differences. Springer, Cham. (2016) https://doi.org/10.1007/978-3-319-28099-8_1071-1 